\title{
Naturopathy: The Evocative Prelude to a New Face of Dentistry
}

\author{
Sumit Munjal ${ }^{1 *}$, Seema Munjal ${ }^{2}$ and Fathima Firdose ${ }^{3}$ \\ ${ }^{1}$ Department of Periodontics, Institute of Dental Studies and Technologies, Modinagar, Uttar Pradesh, India \\ ${ }^{2}$ Department of Prosthodontics and crown \& bridge, Faces $n$ Braces Dental Research Centre, New Delhi, India \\ ${ }^{3}$ Private Practitioner, India
}

Submission: May 15, 2020; Published: June 19, 2020

*Corresponding author: Sumit Munjal, Department of Periodontics, Institute of Dental Studies and Technologies, Modinagar, Uttar Pradesh, India

\begin{abstract}
In naturopathy, the ideology and methods are based on vitalism and folk medicine, rather than evidence-based medicine. Lately it is practiced in many countries like India, United States, Canada, Switzerland, and United Kingdom, but it is subject to different standards of regulation and levels of acceptance. People everywhere are turning increasingly towards a natural, healthy lifestyle. Recent analyses done on patients are enthralling enough to be probed as a counterpoint for the criticism faced so far. Naturopathic remedies are exceptionally helpful in patients who are apprehensive of undertaking dental treatment and in cases not responding to conventional treatment, despite several follow-ups. Above all, this innocuous and holistic method of practice has gained reverence for alleviating symptoms in chronic dental abnormalities, beside malignancies in general.
\end{abstract}

Keywords: Naturopathy, Dentistry, Holistic, Oral diseases

Abbreviations: COFP: Chronic orofacial pain disorders; EBM: Evidence-based medicine; AYUSH: An acronym for Ayurveda, Yoga and Naturopathy, Unani, Siddha and Homeopathy; NRHM: National Rural Health Mission; NPLEX: Naturopathic Physicians Licensing Examinations; NABNE: North American Board of Naturopathic Examiners; CNME: Council on Naturopathic Medical Education; RCT: Randomized control

\section{Introduction}

Cicero, the great Roman orator, very rightly said "Not to know what has been transacted in former times is to continue always as a child. If no use is made of the labours of the past ages, the world must remain in the infancy of knowledge." The disease in various forms, have afflicted mankind since the dawn of history [1]. In the present era with modern lifestyle, the chronic orofacial pain disorders (COFP) are highly prevalent alongside stressful conditions involving head, face, and neck. This necessitates the oral physician to have a detailed knowledge of non-odontogenic pain for proper diagnosis and a multidisciplinary approach for management. Inappropriate treatment often leads to no improvement in patient's condition and hence worsens the scenario [2]. A number of unconventional methods are being used in dentistry including regulation thermography, homeopathy, Nosode therapy, acupuncture, magnetic field therapy, ozone therapy, Mora therapy, and lymph drainage [3].

Naturopathy is a form of alternative medicine that employs an array of pseudoscientific practices. The ideology and methods are based on vitalism and folk medicine, rather than evidence-based medicine (EBM) [4]. Lately it is practiced in many countries like
India, United States, Canada, Switzerland and United Kingdom, but it is subject to different standards of regulation and levels of acceptance. With an aim to expand the dimension of these medicine systems the Government of India in 1995, established the concept, which was later renamed as AYUSH, an acronym for Ayurveda, Yoga and Naturopathy, Unani, Siddha and Homeopathy (Figure 1). Since then, Indian doctors have witnessed a milestone of promotion by integrating AYUSH into local health traditions in the National Rural Health Mission (NRHM).

\section{Historical Background}

The term naturopathy originates from "natura" (Latin root for birth) and "pathos" (Greek root for suffering) to suggest "natural healing" [5]; with its roots in the $19^{\text {th }}$ century Natural Cure movement of Europe [6]. Benedict lust, who is considered to be the father of US naturopathy, (Figure 2) was in turn introduced into health practices in Germany, by Father Sebastian Kneipp (Figure 3). Lust defined it as a broad discipline rather than a particular method, and included such techniques as hydrotherapy, herbal medicine, and homeopathy, as well as eliminating overeating, tea, coffee, and alcohol. He described the body in spiritual and 


\section{Advances in Dentistry \& Oral Health}

vitalistic terms with "absolute reliance upon the cosmic forces of man's nature". After a period of rapid growth, naturopathy went into decline for several decades after the 1930s. The Beginning of the 1970s saw a revival of interest in the United states and Canada and it subsequently gained reverence worldwide almost three decades later.

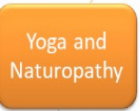

Figure 1: Integration of AYUSH Concept into medicine.

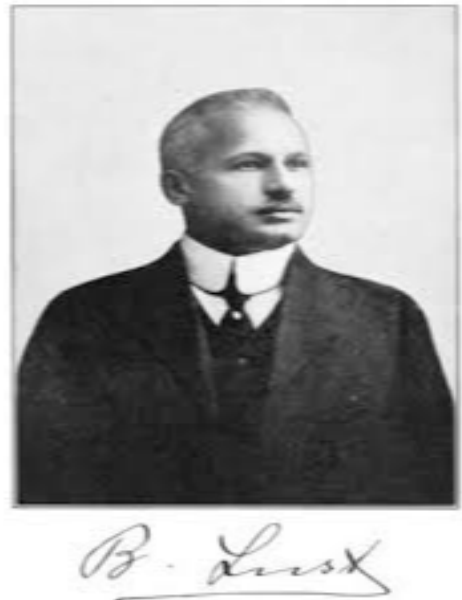

Figure 2: Benedict Lust, The father of naturopathy practice.
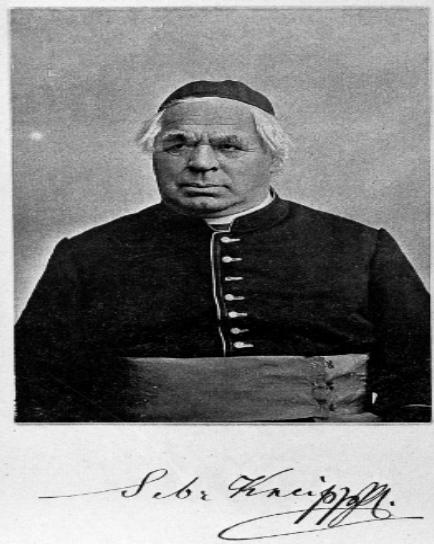

Figure 3: Sebastian Kneipp, Founder of naturopathic system. 


\section{Methodology}

The practice of naturopathy is based on a belief in the body's ability to heal itself through a special vital energy or force guiding bodily processes internally, thus recommend exposure to naturally occurring substances, such as sunshine, herbs and certain foods (Figure 4). A healthy diet rich in vitamins is indispensable in maintaining a natural and functional dentition. In particular, Vitamin C is pivotal to retain the periodontal vigour besides, an essential antioxidant to maintain normal metabolic processes and homeostasis within the body. Severe deficiency in humans results in scurvy; a disease characterized by haemorrhagic diathesis and delayed wound healing [7]. The Oral manifestations include bleeding, ulcerated and swollen gingiva, secondary bacterial infections and ultimately loosening of teeth. The activities such as exercise, meditation and relaxation are the next important naturopath's proposition. Grandiose claims made of successfully addressing cancer and complex chronic musculoskeletal abnormalities have invoked special attention, though a substantial evidence is awaited. By all means, the acupuncture, homeopathy [8], applied kinesiology, ozone therapy [9], chelation therapy [10], iridology, rolfing, massage therapy and traditional Chinese medicine are helpful for the above said disabilities.

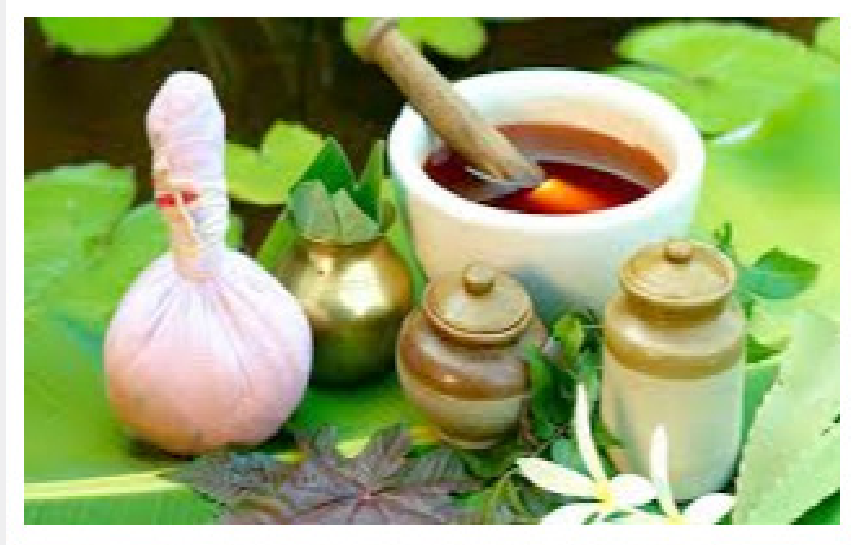

Figure 4: The traditional preparations of medicine.

\section{Education}

Licensed naturopaths must pass the Naturopathic Physicians Licensing Examinations (NPLEX) administered by the North American Board of Naturopathic Examiners (NABNE) after graduating from a program accredited by the Council on Naturopathic Medical Education (CNME). In India, naturopathy is overseen by the Department of AYUSH, under which there is a $5 \frac{1}{2} 2$-year degree in Bachelor of Naturopathy and Yogic Sciences (BNYS) offered by twelve colleges in India. National Institute of Naturopathy in Pune is a prestigious institution encouraging propagation of the existing knowledge and its application through research.

\section{Discussion}

Today, the escalating costs of drugs and several adverse effects associated with modern medicines have led to the search and revival of alternative, indigenous systems of medicines all over the world. This movement towards other systems is patient led. People everywhere are turning increasingly towards a natural, healthy lifestyle. Of utmost concern is that the new outlook is lambasted by the medical societies for the dearth of ample evidence yet. In 2004, a survey conducted in this regard, which determined that most commonly prescribed therapeutics in Washington state and Connecticut were botanical medicines, vitamins, minerals, homeopathy, and allergy treatments [11].

Another examination published in 2011 found that homeopathy, botanical medicine, nutrition, acupuncture, lifestyle counselling, and detoxification were the most commonly advertised therapies [12]. Naturopathic remedies are exceptionally helpful in patients who are apprehensive of undertaking dental treatment and in cases not responding to conventional treatment, despite several follow-ups. Recent analyses like recent randomized controlled trial (RCT) done on patients with chronic orofacial pain, is enthralling enough to be probed as a counterpoint for the criticism faced so far. Conclusions drawn were that the holistic approaches are useful means in treating patients with chronic orofacial pain as it eliminates the risk of adverse effects associated with long term use of muscle relaxants and anti convulsants [13]. Judging by the immense popularity of medical systems such as Ayurveda, Naturopathy and Yoga over the past two or three decades, it is obvious that these systems offer the promise of cure [14]. These efforts by various stake holders could help us to make dentistry much safer, affordable, and more accessible to all strata of population irrespective of their socioeconomic status.

\section{Conclusion}

Integration of traditional medicine with conventional one is ever- increasingly sought for the patient's complete wellness. On 
one hand, scientific validation and evidence-based clinical trials on these allied medicines should be carried out in dental fields, on other hand awareness among the general population about the benefits of the same should be highlighted to gain confidence for use in prevention and treatment of dental disorders.

\section{References}

1. Munjal S, Munjal S (2014) Evolution of Periodontics: An insight into the past. IJBAMS 4: 21-28.

2. Myers CD, White BA, Heft MW (2002) A review of complementary and alternative medicine use for treating chronic facial pain. JADA 133(9): $1189-1196$

3. Oepen I (1992) A critical evaluation of unconventional diagnostic and therapeutic methods in dentistry. Fortschr Kieferorthop 53(4): 239246.

4. Jagtenberg T, Evans S, Grant A, Howden I, Lewis M, et al. (2006) Evidence - based medicine and naturopathy. Journal of Alternative and Complementary Medicine 12(3): 323-328.

5. Jarvis, William T (2007) NCAHF Fact Sheet on Naturopathy. National Council Against Health Fraud.

6. Brown PS (1998) Nineteenth-century American health reformers and the early nature cure movement in Britain. Medical History 32(2): 174 194

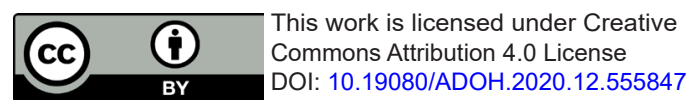

7. Munjal S, Munjal S (2014) Vitamin c and oral health. Recent concerns on supplementation and toxicity. RJPBCS 5: 617-624.

8. Eames S, Darby P (2010) Homeopathy and its ethical use in dentistry. Br Dent J 299-301.

9. Russell Jill, Rovere Amy (2009) American Cancer Society Complete Guide to Complementary and Alternative Cancer Therapies (Second ed.). Atlanta: American Cancer Society pp. 116-119.

10. Atwood IV, Kimball C (2004) Naturopathy, pseudoscience, and medicine: Myths and fallacies vs truth. Medscape General Medicine 6 (1): 33.

11. Boon Heather S, Cherkin Daniel C, Erro Janet, Sherman Karen J (2004) Practice patterns of naturopathic physicians: Results from a random survey of licensed practitioners in two U.S. States. BMC Complementary and Alternative Medicine 4: 14 .

12. Caulfield, Timothy, Rachul, Christen (2011) Supported by science? What Canadian naturopaths advertise to the public? Allergy, Asthma \& Clinical Immunology 7: 14.

13. Bhalla K, Kamarthi N, Malik SS, Goel S, Gupta S (2019) Comparison of conventional pharmacological therapy and holistic approaches (Naturopathy and Yoga) in the management of chronic orofacial pain: A randomized controlled study. J Indian Acad Oral Med Radiol 31: 29-35.

14. Jacobs MS (2013) Psychological factors influencing chronic pain and the impact of litigation. Curr Phys Med Rehabil Rep 1: 135-341.

Your next submission with Juniper Publishers will reach you the below assets

- Quality Editorial service

- Swift Peer Review

- Reprints availability

- E-prints Service

- Manuscript Podcast for convenient understanding

- Global attainment for your research

- Manuscript accessibility in different formats

(Pdf, E-pub, Full Text, Audio)

- Unceasing customer service

Track the below URL for one-step submission https://juniperpublishers.com/online-submission.php 